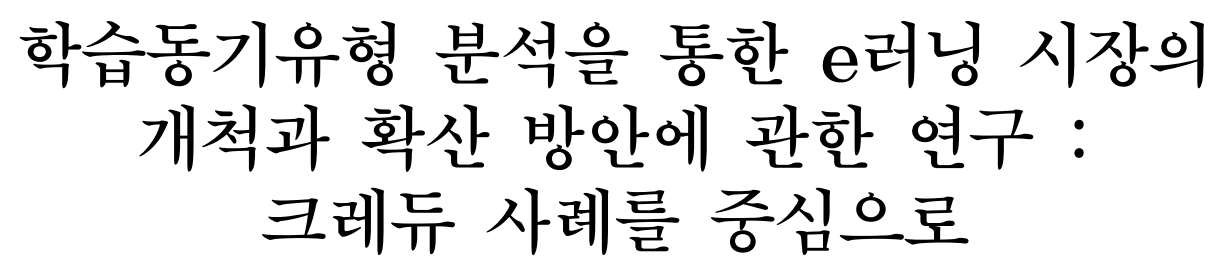

\title{
The Study on development of e-Leaming Market through Analysis of the Type of Leaming Motives : Focused on the Case of Credu
}

\author{
김남국 $\left(\right.$ Namkuk Kim)*, 이준기(Zoonki Lee) ${ }^{* *}$, 정창욱(Changuk Jung) ${ }^{* * *}$, \\ 김종혁 (Jonghyuk Kim) ${ }^{* * *}$
}

\section{초 록}

\begin{abstract}
본 연구는 국내 e러닝 시장을 개척한 기업인 크레듀가 어떻게 시장 진입 기회를 포착하였으며 핵심역량 강화와 함께 어떻게 다각화를 추진하였는가를 실제 사례와 함께 학습자의 e러닝 학습동기유형을 분석하여 살펴보고 기업 차원에서 여러 가지 e러닝 기법들이 어떻게 발전해왔고, 또한 이것을 적용하는 방식에서 어떠한 대응이 필요했는지를 조사하였다. e러닝 시장에서 치열한 경쟁이 펼쳐지고 있는 가운데, 크레듀는 핵심역량을 유지하고 강화하기 위해 고객과 적극적인 의사소통 채널을 만들어 핵심 사업 분야에 대한 집중적인 투자를 단행하면서 학습자의 개인적 특성을 파악하고 학습동기유형에 대한 모델을 만들어 보다 모험적이고 실험적인 제품과 서비스를 출시해 e러닝 발전에 기여했으며 경쟁 우위를 유지할 수 있었다. 본 연구는 소비자의 e러닝 학습동기유형을 분류한 선도적인 연구일 뿐만 아니라 성공한 e러닝 기업의 사례를 통한 e러닝 시장의 개척과 확산 방안에 관한 기법을 소개함으로써 실무적인 측면에서 그 가치가 높을 것으로 기대한다.
\end{abstract}

\begin{abstract}
The study investigated how did Credu pioneer Korean e-Learning market and reinforce their core competencies and how did they promote business diversification analyzing type of learning motives and examining Credu real cases. Under the fierce competition in the current $\mathrm{e}$-Learning market, Credu has maintained their core competencies and strengthened an active communication channels with customers with focusing on investment to core businesses. Credu has introduced more adventurous and challenging products and services with creating a new model for the types of learning motives. This study could introduce the new perspective about the type of learning motives in e-Learning area. Also, the case study of successful e-Learning company, Credu, could contribute to make more spread

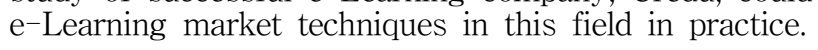

키워드 : 크레듀, e러닝, 학습동기유형 분석, 핵심역량, 다각화, 경쟁전략

Credu, e-Learning, Analysis of Type of Learning Motives, Core Competency, Diversification, Competition Strategy

\footnotetext{
* $\quad$ First Author, Dong-A Business Review

** Correspoding Author, Graduate School of Information, Yonsei University(E-mail: zoonki@gmail.com)

*** $\mathrm{Co}-$ Author, Republic of Korea Air Force Academy

**** Co-Author, Graduate School of Information, Yonsei University

2013년 07월 04일 접수, 2013년 08월 02일 심사완료 후 2013년 08월 14일 게재확정.
} 


\section{1. 서 론}

정보화가 급진전하면서 인터넷을 활용한 $\mathrm{e}$ 러닝 시장은 꾸준한 성장세를 보이고 있다[21]. 산업통상자원부와 정보통신산업진흥원의 '2012 e러닝 산업 실태조사'에 따르면 한국 e러닝 산업의 2012년 총 매출액은 전년 대비 $12.1 \%$ 증가한 2 조 7478 억 원을 기록했으며 기업 당 평균 매출액도 17 억 원으로 전년대비 $15 \%$ 상승했다. e러닝 산업의 매출액은 지난 2009 년 2조 910억 원에서 2010년 2조 2458억 원 으로 지속적인 성장세를 보이고 있다. 이 같 은 e러닝 산업의 발전은 기존 오프라인 교육 의 시간적, 공간적 한계를 뛰어넘어 학습자의 상황과 선호에 따라 강의 시간이나 속도 등 을 조절할 수 있는 개인화된 교육 서비스로 서의 장점을 지니고 있다[12].

전통적인 오프라인 교육 시장이 아닌 컴퓨터 와 인터넷을 활용한 e러닝 시장이 급속하게 발 전할 수 있게 된 데는 빠르게 변화하는 현대 사회에 대처하기 위한 자기계발의 필요성 증가 와 시간 또는 비용의 절약과 같은 효율성 및 편의성 도모에서 그 이유를 찾을 수 있다. 실제 로 교육과학기술부 조사에 의하면 e러닝을 이 용하는 사람들은 이를 통해 취업이나 승진, 이 직, 창업과 같은 직업적 측면에서의 실질적인 도움을 받을 수 있을 뿐만 아니라, 교양함양, 지식습득과 같은 개인적 측면에서의 자기계발 도 비교적 싼 가격에 온라인상의 여러 채널을 통해 이용할 수 있다는 데 가장 큰 이점이 있다 고 밝혔다. 즉, e러닝을 이용하는 사람들의 구체 적인 학습동기요인을 조사하는 것으로 e러닝 이 더욱 발전할 수 있는 계기를 마련할 수 있고, 지속적인 사용의 확산을 도모할 수 있을 것이
라 예상할 수 있다. 이에 학습동기분석에 대한 여러 가지 이론을 밝히고, 개인의 특성(Personality) 및 컴퓨터를 기반으로 한 e러닝의 특징을 정의 하는 것이 필요하다.

또한, e러닝 시장에서 가장 두드러진 실적을 기록하고 있는 회사인 크레듀에 대한 전략 및 우수 사례를 조사하여 e러닝 시장의 확산에 더 욱 실질적인 방안을 제시할 수 있을 것이다. 크 레듀는 e러닝 교육업체를 표방하며 지난 2000 년 설립된 후 불과 몇 년 사이에 꾸준한 성장세 를 보이며 2012년 795억 원의 매출을 올렸다. 크레듀는 삼성그룹 인력개발원에서 분사해 독 립 법인으로 출발한 후 온라인 기업 교육 시장 을 집중 공략하며 성장을 지속했으며 연관 분 야로 효과적인 사업 다각화를 추진했다. 하지 만 출발 초기부터 e러닝 시장은 여러 업체들이 치열한 경쟁을 벌여왔으며 시간이 지날수록 경 쟁 강도는 더욱 높아졌다. 크레듀는 이런 환경 속에서 핵심 사업을 강화하면서 새로운 e러닝 방법을 선도적으로 개발하고 관련 사업으로 영 역을 확대해왔다. 본 연구에서는 크레듀 사례 를 통해 e러닝 기법이 어떻게 발전해왔고, 새로 운 유형의 서비스를 개발하는 과정에서 직면했 던 어려움을 어떻게 극복했는지를 살펴봄으로 써 e러닝 기법의 발전 방향과 기업의 대응 전략 에 대한 시사점을 밝히고자 한다.

\section{2. 이론적 배경}

\section{1 학습동기요인에 대한 이론}

학습동기요인은 크게 네 가지로 분류가 가능 하다. 첫째, 개인의 성숙(Personal growth)을 
위한 목적이다. 이는 자기 개발과 새로운 환경 에 스스로를 적응시키려는 노력으로 자기 중심 주의적 사상이 바탕이 된다[16, 17]. 또한 이러 한 자기 개발을 위한 노력은 자기효능감(Selfefficacy)을 높여 학습에 의한 개인의 성숙을 더 욱 공고히 해준다[3]. 두 번째로 사회적 관계 (Belonging)에서 학습동기요인을 찾을 수 있다. 즉, 학습 참가자는 자신의 시간을 투자하는 대 신 다른 참가자와의 의미 있는 감정적 교류를 쌓을 수 있으며, 이를 통해 참가자들 간의 사회 적 네트워크를 형성하게 된다 $[5,6]$. 이러한 과 정을 통하여 모든 학습 참가자는 자신의 인생 에 있어 가장 중요한 인적 네트워크를 형성해 나갈 수 있다. 세 번째 학습동기요인으로 사회 적 비교와 학습 참가자 간 경쟁을 들 수 있다. 이는 통상적으로 성취동기와 관계가 있는데, 예를 들면, 사회적 우위를 점하려 하고 다른 사 람들보다 강한 의지로 한 단계 진보하려는 노 력으로 인해 새로운 기술을 배우고 능력을 쌓 으려 한다는 것이다[8,10]. 이러한 경향으로 인 해 성취동기는 나이가 어릴수록 더욱 강해지는 경향이 있다[13, 19]. 마지막으로 학습은 도구적 동기(Instrumental motivation)와 관련이 있고 [9, 27], 도구적 동기는 학습의 결과로써 기대할 수 있는 가치와 연결된다. 즉, 학습자는 학습으 로 인하여 직장에서 사회적 성공을 이룰 수 있 고 이를 통해 장기적인 관점에서 인생의 성공 또한 보장받을 수 있다. 즉 도구적 동기에서 도 구란 학습의 성공적인 결과이자 사회적 성취를 의미한다.

\section{2 온라인 기반 e러닝}

빠른 속도로 발전하고 있는 온라인 기반 e러
닝은 ICT를 이용한 새로운 형태의 학습 체계로 [4], 학습자로 하여금 학습에 관한 자기결정 (Self-Determination)에 있어 좀 더 많은 기회 를 제공해 줄 수 있다. 즉, 언제 어디서는 학습자 가 원하는 때에 반복적으로 학습을 할 수 있는 것을 의미하며, 이러한 특성으로 인해 최근의 학습 체계 경향에 더욱 부합한다고 할 수 있다 [2]. 실제로 최근의 한 연구에 의하면 메타 분석 결과 e러닝은 학습자 지향적이고 능동적인 효 과를 가진다고 한다[20].

\section{3 개인의 특성(Personality)과 학습 동기}

학습요인동기를 파악하는 중요한 요소는 개인의 특성에 있다. 개인의 특성은 개방성 (Openness), 성실성(Conscientiousness), 외향 성(Extraversion), 친화성(Agreeableness), 신 경증(Neuroticism)의 5가지의 요소로 구분될 수 있으며[23], 이러한 요소들이 어떻게 조합을 이루는가에 따라 학습동기요인이 달라질 수가 있다. 예를 들면, 기본적으로 능동적인 성격의 소유자는 학습에 있어서도 적극적인 태도를 나 타내며, 이는 개인의 특성 요소 중 낮은 단계의 신경증과 높은 단계의 외향성, 친화성, 개방성 과 관계가 깊다[11]. 또한, 높은 단계의 외향성 과 목적의식은 학습과 관련하여 사람들의 지적, 문화적, 사회적 활동과 깊은 관계가 있고 이로 인하여 학습 효과는 더욱 긍정적이게 나타난다 [1]. 다른 연구에서도 긍정적인 성격의 소유자 가 더욱 향상된 인지적 능력을 갖는다는 결과 를 나타내고 있다[18]. 즉, 개인의 특성에 관한 연구를 통하여 e러닝 학습동기요인을 더욱 철 저하게 규명할 수 있고, 이는 곧 e러닝 시장의 
확산에 긍정적인 영향을 줄 수 있을 것이라 판 단할 수 있다.

\section{3. 사례 연구}

\section{1 사업의 초기 단계}

크레듀의 모체는 삼성그룹 임직원의 교육 을 담당하고 있는 삼성인력개발원의 열린교육 팀이다. 하지만, 창업 초기, 삼성 이외의 다른 민간 기업이나 공기업을 대상으로 영업 활동을 확대하였다. 영업 담당 직원들은 삼성 그룹의 축적된 교육 노하우를 다른 기업들도 활용할 수 있다는 점에서 크레듀의 서비스가 차별적 경쟁우위를 가질 것이라고 판단하였다.

이에 따라 영업활동을 할 때 '60년 삼성의 교 육 노하우 전수라고 하는 캐치프레이즈를 이용 하였다. 크레듀는 교육 콘텐츠 제공과 관련한 사업 모델을 네 가지로 결정하였다. 첫번째 모 델은 여러 분야의 교육 콘텐츠를 회사별 웹사 이트에 개설해주고 임직원들이 자율적으로 선
택해서 수강을 유도한 후 수강한 콘텐츠에 대 해 회사측이 크레듀에 비용을 지불하고, 회사 측은 고용보험 환급을 받는 형태의 사업 모델 을 만들었다. 크레듀는 이를 '자체과정'이라는 용어로 명명하였다. 둘째, 전 직원이 반드시 받 아야 하는 교육, 즉 정보보호나 윤리경영, 성희 롱 예방, 회사의 철학과 미션 가치와 관련한 교 육의 경우, 오프라인에서 직원들을 모아놓고 교육할 때 상당한 비용이 든다는 점에 착안하 여, 일정 수강 인원을 고객 회사가 보장해준다 는 전제를 바탕으로 콘텐츠 개발을 무료로 해 주었고 후에 고용보험 환급을 통해 수익성을 확보하는 형태의 사업을 시작하며, 이러한 기 법을 ‘공동과정’으로 명명하였다. 뿐만 아니라, 셋째, 이미 교육 시스템을 모두 갖고 있는 회사 나 공공기관에 대해 크레듀가 교육 콘텐츠만 공급해주는 사업 모델도 마련했는데 이를 ‘수주 과정'이라고 불렀다. 마지막으로 토익이나 토플 같은 어학 프로그램의 경우 외부 제작자들의 콘텐츠를 가져와 기업에 판매하는, 즉 크레듀 가 일종의 콘텐츠 유통업자가 되는 모델도 만 들었다. 이는 '도입과정'으로 명명하였다.

〈Table 1〉Business History

\begin{tabular}{c|l}
\hline Period & \multicolumn{1}{c}{ Business History } \\
\hline 2000. 05 & Established Credu Co. (with paid-in capital KRW 2 billion) \\
\hline 2003. 03 & $\begin{array}{l}\text { Operated iMBA, the business school of Sungkyunkwan University acquired LMS } \\
\text { international standard 'SCORM' }\end{array}$ \\
\hline 2005. 01 & Opened the industry's first blended learning venue CREDU Campus \\
\hline 2006. 05 & Surpassed the KRW 100 billion mark as the first in the industries \\
\hline 2007.01 & Invest in LTI, Inc. USA \\
\hline 2007.08 & Began offering e-learning service to Europe market \\
\hline 2010. 04 & Made an agreement with The Korea Chamber of Commerce \& Industry about OPIc Center \\
\hline 2012.07 & Made an agreement Credu-Ulsan Institute of foreign language education \\
\hline 2012.09 & Made an agreement with NEC Learning to launch OPIc in Japanese market \\
\hline
\end{tabular}


교육 콘텐츠 서비스 외에도 학습경영시스 템(LMS : Learning Management System)라 불리는 교육 시스템 구축 사업도 시작했다. 이 러한 시스템 구축 활동은 '삼성 사이버 유니버 시티' 등 온라인 교육 시스템을 구축해본 경험 과 노하우를 바탕으로 하였으며, 이를 사업화 해 추가 매출을 올리고, 교육 서비스의 안정적 제공을 꾀하였다. 또한, 한국 최초로 사이버 교 육 시스템을 구축했고 이후에도 안정적으로 시 스템을 운영해왔다는 점을 강조하며 교육 시스 템 구축 분야에서 적극적인 영업활동을 벌였으 며, 이러한 노력으로 2000년 중앙공무원 교육원
의 학사관리 시스템 구축 사업을 수주하는 성 과를 올리기도 하였다. 그러나 온라인 교육 시 장에서 사업기회를 본 것은 크레듀만이 아니었다. 다른 업체들도 온라인시장의 성장 잠재력이 높 다고 판단, 경쟁적으로 e러닝 사업에 뛰어들기 시작하였다. 크레듀가 e러닝 사업을 시작할 당 시 배움닷컴, 아이빌소프트, 캠퍼스 21 , 사이버 $\mathrm{MBA}$, 휴넷, 삼성SDS의 멀티캠퍼스 등이 유사 한 사업을 시작하였으며 동시에 기업 교육 시 장을 공략했다. 또 대기업의 경우 SK 연수원과 현대인재개발원, $\mathrm{LG}$ 인화원 등은 자체 교육 프 로그램을 운영해 고용보험 환급을 받고 있었다.

$\langle$ Table 2〉 Business Section

\begin{tabular}{|c|c|c|}
\hline Section & Item & Business \\
\hline \multirow{6}{*}{$\begin{array}{c}\text { Infra } \\
\text { Business }\end{array}$} & e-learning service & $\begin{array}{l}\text { 1,200 e-learning Contents - Management leadership, foreign language, } \\
\text { Information Technology, and etc. } \\
1,400 \text { member companies }\end{array}$ \\
\hline & $\begin{array}{l}\text { Multi-telecom serv- } \\
\text { ice }\end{array}$ & Educational program with over 600 books to improve job performance \\
\hline & Blended learning & On-off blended program for work leaders \\
\hline & HR consulting & Perfomance evaluation solution on $\mathrm{HR}$ \\
\hline & $\begin{array}{c}\text { Contents develop- } \\
\text { ment }\end{array}$ & 200 contents developed per year with educational scientist \\
\hline & LMS development & LMS service development \\
\hline \multirow{6}{*}{$\begin{array}{l}\text { Strategic } \\
\text { Business }\end{array}$} & Global business & Educational service for foreign area (China, Japan, and Europe) \\
\hline & M-Kiss & Knowledge service for soldiers and their family \\
\hline & Teachers'training & e-learning training for teachers \\
\hline & $\begin{array}{c}\text { Financial specialist } \\
\text { certification }\end{array}$ & Course for $\mathrm{CFP}, \mathrm{AFPK}, \mathrm{CFA}$, certification \\
\hline & iMBA & Sungkyunkwan Univ. online MBA course \\
\hline & Value MBA & Sungkyunkwan Univ. MBA course \\
\hline \multirow{5}{*}{$\begin{array}{c}\text { New } \\
\text { Business }\end{array}$} & OPIc & English speaking evaluation business \\
\hline & Univ. business & e-learning contents and solution service on Univ. \\
\hline & m-learning & High tech network development like DMB, wibro, IPTV \\
\hline & $\mathrm{HRO}$ & Educational planning, course development, operation, evaluation on HR \\
\hline & Book publish & Book publish with variety contents \\
\hline
\end{tabular}


삼성 계열사인 삼성SDS 멀티캠퍼스의 경우 크 레듀 설립 당시, IT 관련 교육에 특화하고 경영 이나 리더십 등 일반 기업 교육은 크레듀가 담 당한다는 삼성 모기업의 원칙에 따라 초기 교 육 콘텐츠 사업에서는 별다른 충돌이 일어나지 않았다. 하지만 시간이 지나면서 삼성SDS의 멀티캠퍼스와 외국어 교육 분야에서 경쟁이 이 뤄지다가 엑셀 파워포인트 분야의 교육에도 두 회사가 모두 진출하면서 경쟁 구도가 정착됐으 며, 2003년 이후부터는 사실상 온라인 교육 사 업 전 분야에서 경쟁하기 시작하였다. 또 배움 닷컴과 아이빌소프트는 동영상 중심의 강의를 제작하며 기업 대상의 영업을 본격화하고 있었다. 특히 일부 경쟁 업체는 콘텐츠 제작 도구를 개 발해서 시장에 대량으로 판매하면서 영향력을 확대하고 있었다.

\section{$3.2 \mathrm{e}$ 러닝 콘텐츠 차별화}

e러닝의 가장 큰 장점 중에 하나는 개인화된 교육을 제공할 수 있다는 점이다[26]. e러닝을 통해 교육 효과를 극대화하려면 이용자들의 개 별적인 상황이나 요구를 반영해 가장 최적화된 콘텐츠를 제공할 수 있는 다양한 기법들을 활 용하는 것이 바람직하다[15]. 하지만 크레듀의 경우 초기부터 e러닝 콘텐츠의 개인화를 추구 했던 것은 아니다. 크레듀를 비롯한 대부분의 $\mathrm{e}$ 러닝 업체들은 오프라인 강의와 파워포인트 슬라이드를 단순하게 온라인에 옮겨놓는 형태 의 콘텐츠로 출발했다. 당시 대부분 기업 대상 의 온라인 교육업체들은 강사의 강의를 녹화해 동영상으로 재생시켜주면서 그 옆에 파워포인 트 화면을 보여주는 형태로 콘텐츠를 제작했다. 크레듀도 초기에 이런 형태의 콘텐츠를 제작했다.
이런 동영상 강의 방식은 장단점을 모두 갖고 있다. 무엇보다 가장 큰 장점은 제작비가 저렴 하다는 것이다. 강사는 평소처럼 강연을 진행 하면 되고, 사전에 준비된 파워포인트 자료만 강의 진행 속도에 맞게 보여주면 되기 때문에 디자이너가 별도의 삽화나 시각물을 따로 제작 할 필요가 없다. 또 미리 정해진 포맷을 그대로 활용하기 때문에 추가적인 작업이 많지 않고 따라서 비용이 적게 든다. 만약 학습자의 학습 의욕이 높은 경우 이런 방식으로도 효과를 볼 수 있다. 일정 점수 이상을 얻어야 하는 토익 (TOEIC)과정이나 전문 자격증 취득처럼 확실 한 목표를 갖고 온라인 교육을 받을 경우 학습 자는 동영상 강의에 몰입한다. 실제 사업 초기 크레듀는 삼성 인력개발원 시절 제작했고 그룹 관계사에 서비스했던 영어, 마케팅기초, 관리자 기초, 리더십기초, 회의운영 기법 등 30 개 강좌 를 갖고 출발했는데 대부분은 동영상 중심으로 제작됐다. 하지만 외국어나 자격증 시험과 달 리 기초 이론이나 일반적인 직무능력 향상 관 련 교육을 받을 경우 동영상 강의는 여러 문제 점을 유발한다. 우선 학습자의 확실한 동기나 목표가 부족한 경우가 많아 동영상을 켜놓고 다른 일을 할 수 있다. 회사에서 의무적으로 과 정을 이수하라고 독려하더라도 동영상을 켜놓 고 주의를 기울이지 않을 공산이 크기 때문에 실질적인 교육 효과가 떨어질 수 있다. 또 오프 라인과 달리 e러닝 강의는 강연자와 교습자 간 상호작용을 하기 매우 어렵다 $[22,28]$. 특히 e러 닝은 직접 사람을 보고 하는 의사소통과 달리 비언어적 커뮤니케이션이 매우 어렵기 때문에 의사소통의 제한이 나타나며[14], 학습자들의 인지 부하(cognitive load)를 가중시킬 수 있다 [24]. 이런 문제점을 극복하기 위하여 새로운 교 
습 방법을 고안하였고, 이는 빠른 시간 안에 인 력을 훈련시켜 제조와 영업 등 생산 활동에 투 입하는데 유용한 교육 철학인 행동주의 교육 관점에서 개인의 경험에 의해 구체적인 문제 상황을 스스로 해결할 수 있도록 하는 구성주 의 교육 방식으로 전환하였다. 구성주의적 관 점에서 교육 콘텐츠를 제작할 경우 많은 장점 이 있다. 동영상 강의처럼 일방통행 식 강의가 아니라 교습자가 다양한 가능성에 대해 생각하 고 판단해야하기 때문에 교육 과정에서 상당한 상호작용이 이뤄진다. 또 주어진 과제를 해결 해야 다음 단계로 넘어가기 때문에 교습자가 동영상을 켜놓고 주의를 기울이지 않는 부작용 도 예방할 수 있으며 학습자 개인의 시간적 공 간적 제약을 감안해 원하는 정보를 제공할 수 있다는 점에서 개인화 서비스로서의 장점도 향 유할 수 있다[25]. 하지만 구성주의 도입에 따른 단점도 있다. 무엇보다 비용이 가장 큰 문제다. 동영상 강의의 경우 강사들이 평소와 똑같이 강의를 진행하고 이를 녹화하면 되기 때문에 교육업체가 손쉽게 콘텐츠를 제작할 수 있다. 하지만 구성주의에 바탕을 둔 콘텐츠를 만들려 면 상황별로 매번 강의 자료를 새로 만들어야 한다. 따라서 회사 입장에서는 콘텐츠 제작에 따른 비용 부담이 상당하다.

\section{3 목적지향시스템(GBS : Goal-based System) 모델 도입}

크레듀는 구성주의 이론을 도입한 교육 콘텐 츠를 웹기반훈련(WBT : Web Based Training), 혹은 웹기반학습(WBL : Web Based Learning) 로 명명하였다. 초기 항상 새로운 강의를 준비 해야 하는 강사들을 설득하기 쉽지 않았지만,
피교육자에게 더 큰 효과가 돌아간다는 점을 앞세워 적극 설득하였으며, 구성주의적 관점을 실현할 수 있는 다양한 방식의 콘텐츠 제작을 독려했다. 초기 $\mathrm{WBT}$ 관련 콘텐츠는 비교적 단 순한 플래시나 애니메이션을 사용했다. 특정 메뉴를 클릭해 의견 및 학습 내용과 관련한 피 학습자의 반응을 입력하면 다음 단계로 넘어가 는 형태였다. 하지만 시간이 지나면서 학습자 의 훙미와 관심을 유발할 수 있도록 훨씬 정교 한 플래시나 애니메이션 등이 활용되었다. 또 15 개 안팎의 협력업체들이 적정 수준의 품질을 유지하면서 콘텐츠를 제작할 수 있도록 가격조 건 하나만으로 납품업체를 선정하지 않고 우수 한 콘텐츠 제작 능력을 갖추고 있는지를 핵심 요인으로 고려했다. 크레듀의 새로운 모델에 경쟁사들이 유사한 교육 콘텐츠를 제작하자 $\mathrm{WBT}$ 에서 한 단계 더 진전된 교육 콘텐츠를 개발, 차별화를 모색하였고, $\mathrm{GBS}$ 를 이용하였다. GBS 방식이란 구체적인 사례를 바탕으로 미리 정해진 정답이나 결론을 제시하지 않은 상태에 서 학습자에게 어떤 방식으로 문제를 해결할지 를 묻는 방식이다[7].

WBT보다 한 단계 발전한 이런 방식은 콘텐 츠 제작자들에게 더욱 많은 노력을 요구했다. 학습 목표를 잘 설명할 수 있는 케이스를 발굴 해야 하고, 이를 토대로 정교한 시나리오를 짜 야 하며, 연관된 정보도 다양한 경로를 통해 제 시해야 하기 때문이다. 강사들의 반발도 만만 치 않았다. 케이스를 발굴하고 스토리와 시나 리오를 작성하는 과정에서 과거보다 훨씬 많은 노력을 기울여야 했기 때문이다. 일부 강사들 은 학생들이 동영상 강의를 더 선호하며 피교 육자 스스로 해결책을 찾기 보다는 강사가 명 쾌하게 답을 내려주는 것을 더 좋아할 것이라 
고 주장하기도 했다. 경영진은 교육의 큰 흐름 이 이런 방향으로 나아갈 것으로 믿고 투자를 강행했다. 구성주의 철학이 대세로 자리 잡을 것이란 경영진의 강력한 믿음을 토대로 콘텐츠 개발팀도 새로운 도전에 나서고 싶어 했다. 어 려움이 있었지만 크레듀는 이런 동력을 바탕으로 문제기반학습(PBL : Problem Based Learning) 콘텐츠 제작 편수를 점차 늘려갔다. $\mathrm{PBL}$ 콘텐 츠는 장점이 있다. 학습자가 구체적인 사례를 이해하고 문제 상황에 대한 해결책을 찾도록 유도하면서 교육을 진행하기 때문에 학습 내용 을 쉽게 이해할 수 있을 뿐만 아니라 현장에서 보다 효율적으로 활용할 수 있는 지혜를 얻을 수 있다. 이런 우수성이 입증되면서 크레듀는 $\mathrm{PBL}$ 방식의 교육 콘텐츠를 e러닝 경진대회에 출품해 대상을 받아 앞선 기술력과 교육 콘텐 츠 제작 역량을 가졌다는 평가를 받게 됐다. 하 지만 $\mathrm{PBL}$ 이 자기 주도 학습을 요구하기 때문에 피교육자는 학습 과정에서 스스로 인터넷을 통 해 정보를 찾아보고, 의견을 기입해야 하며, 토 론도 벌여야 한다. 따라서 동영상 강의보다 훨 씬 많은 집중력과 노력을 필요로 한다. 결국, 이를 제대로 따라가지 못한 피교육자가 중간에 과정을 포기하는 경우가 많다. 다른 교육과정에 비해 수료자 비율이 떨어지는 문제가 생겼다. 수료율은 고용보험 환급 비즈니스 모델에서 매 우 중요한 변수다. 수료율이 떨어지면 그만큼 고용보험 환급액이 줄어들어 매출과 이익의 감 소를 가져오기 때문이다. 따라서 크레듀는 자 격증이나 학위 취득, 승진을 위해 반드시 필요 한 교육 등 피교육자가 확실한 동기를 갖고 교 육에 임하는 경우 $\mathrm{PBL}$ 로 콘텐츠를 제작했다. $\mathrm{PBL}$ 콘텐츠의 비율이 높지는 않지만 선도적이 고 실험적인 콘텐츠 제작을 통해 크레듀는 앞
선 기술력을 갖고 있다는 것을 보여줬으며 사 례를 중심으로 학습자가 스스로 문제를 해결 하도록 유도한다는 취지는 다른 교육 콘텐츠 제작 과정에서도 녹아들어가는 등 스필오버 (Spillover) 효과도 발생했다. 또 PBL 제작 과정 에서 축적된 그래픽이나 애니메이션 기법 등도 다른 콘텐츠 제작에서 활용되면서, 전반적인 교육 콘텐츠의 품질을 높이는 계기가 됐다.

\section{4 나인 매트릭스와 유저빌러티 테스트}

크레듀는 교육 콘텐츠 차별화 외에도 교육 효과 향상을 위한 다양한 기법을 도입했다. 대 표적인 예가 2006년부터 나인 매트릭스다. 나 인 매트릭스는 한 축에 학습 수준의 높고 낮음 을 세 단계로, 다른 한 축에는 학습자 수준의 높고 낮음을 세 단계로 구분해놓고, 이를 통해 형성되는 9 가지 조합에 대해 각각 다른 처방을 하는 것이다. 이는 교육 내용과 관련해서 새로 운 기법을 만든 것은 아니다. 하지만, 학습 내용 이나 학습 수준과 상관없이 무차별적으로 일률 적인 교육 방법을 제안했던 것에서 탈피해 학 습자의 수준과 기업의 요구에 맞춰 최적의 교 육 효과를 낼 수 있도록 유도하기 위한 것이다. 교육 콘텐츠 출시 전 수행하는 '유저빌러티 테 스트'도 크레듀 경쟁력의 중요한 한 축을 담당 했다. 크레듀는 교육 콘텐츠 제작이 완료되면 아르바이트 학생이나 자원자를 동원해 이들이 실제 교육받는 과정을 정밀하게 점검한다. 예 를 들어 여러 메뉴 가운데 어떤 것을 더 자주 이용하는지, 교육 과정에서 클릭해야 하는 부 분을 제대로 클릭하는지, 제작자 의도와 달리 학습자가 건너뛰는 부분은 없는지, 학습에 걸 리는 시간은 얼마나 되는지 등을 면밀하게 모 
니터링하고 이를 통해 발견된 문제점을 수정, 상품을 출시한다. 또 이 테스트를 통해 확보한 데이터는 노동부에 학습 시간이 얼마나 되는지 를 입증하는 기초 데이터로도 활용된다. 특히 이런 데이터는 콘텐츠 품질 개선에 상당한 역 할을 했다. 이용자들이 메뉴를 클릭하는 성향 과, 흥미를 갖거나 지루해하는 부분 등을 파악, 콘텐츠 제작 시 이런 점을 반영해 학습효과를 높일 수 있도록 하고 있다. 특히 이런 데이터는 각종 매뉴얼과 가이드라인을 업그레이드하는 데에도 큰 도움이 됐다. 크레듀는 콘텐츠 설계와 $\mathrm{LMS}$ 운영, 디자인 가이드 등 수많은 매뉴얼을 갖고 있으며 꾸준히 이를 업데이트하고 있다. 이 과정에서 컴퓨터 화면을 바라보는 사용자의 눈길이 어떤 상황에서 어디로 향하는지, 어떤 색깔에 더 반응하는지, 어떤 크기의 글자 폰트 가 더 학습내용 전달에 효과적인지 등에 대한 방대한 데이터를 확보해 각종 매뉴얼을 업데이 트한 것이다. 이를 통해 납품 업체들에게도 학 습 효과가 검증된 콘텐츠 제작 방식을 쉽게 전 달할 수 있었고 일관된 품질 관리도 가능했다. 또 매뉴얼을 토대로 제작된 콘텐츠는 LMS 시 스템과 쉽게 연동이 이뤄졌다.

\section{5 첨단 기술을 응용한 콘텐츠 제작}

크레듀는 GBS에 이어 다른 실험적인 교육 콘텐츠 제작도 시도했다. 정보기술 발전으로 인터넷을 통한 혁신적인 영상 구현이 가능해 지면서 크레듀는 실감형 콘텐츠나, 가상현실 을 접목한 콘텐츠, 와이브로와 접목된 유비쿼 터스형 콘텐츠 등을 개발했다. 특히 전자통신 연구원(ETRI)과 함께 증강현실(Augmented Reality) 기술을 적용한 교육 콘텐츠를 개발
하여 특수하게 제작된 교재에 마커를 갖다 대면 화면으로 3 차원 입체 영상이 디스플레 이 되며 줌인, 줌아웃, 회전 등 다양한 측면 에서 영상을 볼 수 있게 되었다. 항공기 정비 나 자동차 정비와 관련한 교육의 경우 실물 없이 온라인상에서 교육하기 어려웠지만 이 런 기술이 본격 활용되면 굳이 실물 부품을 직접 해체하거나 조립하지 않고도 상당한 교 육 효과를 볼 수 있다.

또한, 크레듀는 온라인과 오프라인 교육의 장점을 결합한 블렌디드(Blended) 모델도 추 진했다. 온라인에서 이론 및 지식에 대한 사 전 교육을 받고, 오프라인에서 직접 현장 교 육을 받은 후 온라인에서 다시 후속 교육을 받는 형태의 블렌디드 모델은 비용이 저렴하 고 다양한 지식을 얻을 수 있다는 온라인 교 육의 장점과, 현장 체험과 상호작용을 원활하 게 할 수 있다는 오프라인 교육의 장점을 적 절히 결합한 모델이다. 이 모델은 교육 내용 이 알차고 다양한 체험을 할 수 있다는 평가 를 받으면서 피교육자와 기업 교육 담당자들 로부터 호평을 받았다. 특히 오프라인에서 직 접 상황별 리더십을 시험해보는 등 온라인 교육을 통해 습득한 이론을 현장에서 시험해 볼 수 있는 기회를 제공했기 때문에 온라인 교육의 한계를 효과적으로 극복했다는 평가 도 받았다. 상황 리더십 교육에 대한 호평이 이어지면서 크레듀는 한국베링거잉겔하임과 우리은행, 제일모직, 삼성 $\mathrm{SDI}$, 대교 등 다양 한 기업 고객을 확보했다. 또 코칭의 기술, 문제 해결 방법론, 변화 관리 등 블랜디브 방 식의 다양한 콘텐츠를 추가로 제작했다.

최근에는 블렌디드 러닝의 일환으로 출시한 경영시뮬레이션 게임인 크레듀 경영 게임(CMG 
: Credu Management Game)도 좋은 반응을 얻 었다. $\mathrm{SMG}$ 는 많은 기업들이 임직원 교육을 위 해 재무, 전략, 마케팅 등 각 분야별 교육이 이뤄 지고 있는데, 기업의 다양한 기능을 한 눈에 보 면서 구성원 간 소통을 통해 의사결정을 하는 경험을 갖기는 쉽지 않다는 점에 착안했다. $\mathrm{CMG}$ 는 5명 안팎의 교육생이 한 개 팀을 이뤄 회사를 구성하고 개인별 $\mathrm{PC}$ 로 온라인 시뮬레 이션 프로그램에 접속해 주요 기능별 역할분담 을 해서 팀내 협력과 팀간 경쟁을 통해 생생한 경영 현장의 의사결정을 체험하는 방식으로 이 뤄진다. 게임의 요소를 도입해 재미를 높이면 서 동시에 의사결정의 결과를 즉각 확인할 수 있도록 하는 등의 장치를 통해 교육 과정에서 몰입도와 효과를 높이고 있다. 그러나 블랜디 드 방식의 경우 강사와의 피교육생간 스케줄을 조정해야 하고, 교육 과정이 복잡해 기업의 교 육담당자들에게 상품 구조를 이해시키기 어렵 다는 단점이 있다. 또 오프라인 교육이 들어가 기 때문에 순수 온라인 콘텐츠에 비해 이익 폭 이 상대적으로 적다는 것도 문제로 지적된다.

\section{6 다양한 시스템 구축}

크레듀의 또 다른 중요한 사업 모델 중 하 나는 $\mathrm{LMS}$, 즉 학습 관리 시스템 구축이다. 사 내 교육 콘텐츠를 제공하는 홈페이지를 구축 해주고, 수강신청 등 다양한 업무처리를 지원 하며, 피교육자를 관리하고, 각종 사내 시스 템과 연계해 사무 처리를 도와주는 시스템을 구축하는 사업이다. 이를 위해, 크레듀는 세 가지 측면에 초점을 맞췄다.

첫째, 최종 수요자인 학습자에 초점을 맞췄다. 보통 온라인 교육 콘텐츠의 구매 의사결정은
각 기업의 교육 담당자들이 갖고 있다. 또 시스템 구축도 교육 담당이나 IT 담당자가 갖고 있다. 따라서 많은 온라인 교육업체들은 기업의 구매 결정권을 가진 교육 및 IT 담당자들의 기호에 맞는 서비스를 제공하기 위해 노력했다. 하지 만 크레듀는 이들 뿐만 아니라 최종 소비자인 피교육자들을 관리하는 것도 매우 중요한 과제 라고 판단, 경쟁자들과는 차별화한 시스템을 구축했다. 일례로 크레듀는 내부적으로 한 달 동안 온라인으로 교육받는 수강생들에게 최소 한 9차례는 어떤 형태로든 접촉을 하자는 원칙 을 갖고 있었다. 이를 위해 크레듀의 LMS는 교육 과정을 시작한 피교육자에게 초기에 환영 안내메일을 발송했고, 일정 시간 안에 일정 수 준의 진도가 나가지 않는 경우에는 문자메시지 를 보내 피교육자들의 주의를 환기시켰다. 또 학습자가 질문을 올렸을 때 곧바로 강사에게 전달해 최대한 빨리 답변할 수 있도록 시스템 을 구축했다. 리포트 첨삭 시스템도 갖춰 피교 육자가 제출한 리포트를 강사가 손쉽게 첨삭해 학습 효과를 높이도록 유도했다. 학습자간 원 활한 상호작용이 이뤼지도록 하기 위해 교육 콘텐츠 내에 상대방의 의견을 손쉽게 보고 피 드백 할 수 있는 실시간 토론방, 쪽지함, 질문방 등도 마련했다. 또한, 피교육자들이 활발하게 상호 의사소통할 수 있도록 윕활용 멀티미디어 편집기(WME : Web Multimedia Editing)라는 솔루션도 개발했다. 이 솔루션을 활용하면 피 교육자들은 짧은 동영상에 각종 텍스트나 이미 지를 덧씌울 수 있고 다른 사람들은 이미지나 텍스트가 첨가된 동영상을 볼 수 있게 된다. 일 종의 사용자제작동영상 $(\mathrm{UCC})$ 으로, 동영상 강 의 내용이나 교육과 관련한 영상에 피교육자들 이 다양한 자기표현을 할 수 있도록 유도하기 
위한 것이다. UCC에 대한 관심이 높아지면서 동영상을 중심으로 피교육자들이 손쉽게 상호 작용을 하도록 솔루션을 제작한 것이다.

둘째, 운영자들이 편리하게 $\mathrm{LMS}$ 를 활용할 수 있도록 다양한 기능을 추가했다. 예를 들 어 학습과 관련한 각종 통계를 쉽게 출력할 수 있는 시스템을 갖췄으며 학습자들의 상황 에 맞는 다양한 강의 및 강사 배정도 효과적 으로 이뤄지도록 했다. 학습자들의 전화 상담 도 편리하게 응대할 수 있도록 담당자에게 전화를 분배해주는 시스템은 물론이고 학습 자 이력을 한 눈에 보여주는 정보 제공 시 스템도 구축했다. 설비 투자도 과감하게 단행 했다. 또 리포트 내용의 표절 여부를 손쉽게 판단할 수 있는 소프트웨어도 갖췄다. 교육 과정에서 다른 사람이 제출한 리포트를 적당 히 손질해 제출하는 경우가 많은데 자동으로 이런 표절을 검색해서 발견하는 시스템을 갖 춰 관리자와 강사의 엄정한 학습 관리를 가 능케 한 것이다. 또 학습자가 진도를 제대로 나가지 않을 경우 독려도 하지만, 진도가 너 무 빨리 나갔을 때에도 자동으로 제한을 걸 어주는 시스템도 개발했다.

셋째, 각 기업의 인사관리 시스템과 LMS 가 연동되도록 했다. 인사와 승진 평가 시 각 종 교육 이수 내용을 반영하는 회사가 늘어 나고 있었기 때문에 회사 데이터베이스와 LMS 데이터를 연동시켜 편리하게 인사담당 자들이 직원 교육 관련 정보를 활용할 수 도 록 하였다.

\section{7 핵심역량에 바탕을 둔 사업 다각화}

기업 대상의 온라인 교육사업 외에도 크레듀
는 다양한 분야에서 사업 다각화를 시도했다. 크 레듀는 전문화와 차별화, 표준화 전략을 바탕 으로 '세계 최고의 지식 창조자(The World's Best Knowledge Creator)'가 되겠다는 비전을 갖고 있다. 또 “양질의 콘텐츠와 전문 기술력 을 바탕으로 최고의 $\mathrm{e}-\mathrm{HR}$ 서비스를 창출해 개 인, 조직, 사회에 삶의 질과 가치를 높여준다." 는 것을 미션으로 하고 있다. 이런 비전과 미션 을 실행하기 위해 크레듀는 핵심을 확장하는 형 태의 사업 다각화를 추진해왔다. 즉, 온라인 교 육 콘텐츠와 솔루션 제작 및 판매, 학사관리, 고객 관리 등의 분야에서 축적된 경험과 노하 우를 바탕으로 추가적인 부가가치를 얻을 수 있는 연관 사업을 개척해왔다. 특히 온라인 교 육과 관련한 핵심 사업이라 할 수 있는 e러닝 서비스 분야의 경쟁이 치열해지면서 산업 전 체의 수익률 악화가 우려되고 있기 때문에 핵 심역량을 기초로 한 사업 다각화를 통해 새로 운 활로를 모색했다.

크레듀는 사업 영역을 크게 세 가지로 구분 했다(사업 영역별 세부 내역 참조). 우선 $\mathrm{e}$ 러 닝 서비스와 온·오프라인 교육의 장점을 흡 수한 블렌디드 러닝, $\mathrm{HR}$ 컨설팅 사업, 콘텐츠 개발, LMS 구축 등 온라인 교육과 관련한 핵 심 사업을 '기간사업'으로 정의했다. 또 해외 사업과 교원 연수 및 전문직 종사자를 위한 특 수계층 사업, 온라인 $\mathrm{MBA}$ 사업 등을 '전략사 업'으로 규정했다. 이와 함께 영어 말하기 공 인능력 평가 사업인 OPIc(Oral Proficiency Interview-computer) 관련 사업과, 대학 비즈 니스, 중등 교육 사업, 출판 사업 등을 '신규사 업'으로 분류했다.

이러한 신규사업 중에 전략사업으로 온라인 $\mathrm{MBA}$ 운영이 있다. 아주대에서 온라인 $\mathrm{MBA}$ 를 
최초로 시작한 이후 사업성이 있는 것으로 나 타나자 본격적인 검토를 시작했다. 특히 온라 인 분야에서 다양한 콘텐츠를 제작해본 경험이 있기 때문에 좋은 브랜드를 가진 $\mathrm{MBA}$ 스쿨과 제휴를 추진할 경우 상당한 시너지 효과를 낼 수 있을 것으로 기대하여 성균관대와 온라인 $\mathrm{MBA}$ 과정을 운영하기로 했다. 크레듀는 당초 $\mathrm{MBA}$ 과정 외에 사이버대학 설립도 검토했고 일부 대학이 합작을 권유하기도 했다. 하지만 상당수 대학들이 사이버대학을 이미 설립해 경 쟁이 지나치게 치열한데다 별도법인 설립 등 인허가 절차도 복잡하다고 판단, 사이버대학보 다는 사이버 $\mathrm{MBA}$ 시장에 진출하기로 결론을 내렸다. 성균관대와 크레듀는 교육부 인가를 받아 정식 석사학위를 수여하는 온라인 $\mathrm{MBA}$ 과정을 2003년부터 운영했다. 특히 크레듀는 $\mathrm{GBS}$ 와 블렌디드 모델을 적용한 콘텐츠를 개발 해 다른 사이버 $\mathrm{MBA}$ 과정과 차별화를 시도했다. 학생들이 학위 취득이란 확실한 목적을 갖고 있기 때문에 실험적인 첨단 교육 콘텐츠가 단 순 동영상 강의보다 높은 교육효과를 낼 수 있 을 것으로 판단했던 것이다. 이런 차별화한 콘 텐츠를 바탕으로 온라인 $\mathrm{MAB}$ 과정은 좋은 평 가를 받으면서 매 학기마다 모집정원(200명) 이상의 지원자를 확보하는 등 좋은 성과를 내 고 있다.

크레듀는 또 경기도 안산 영어마을 위탁 운영도 담당하고 있다. 경기도는 영어마을에 적자가 누적되자 민간 기관에 위탁을 주기로 2007년 결정했다. 이 방침에 따라 경기도는 파주와 안산, 양평 등 세 곳의 영어마을에 대 해 민간 위탁 사업자를 선정했다. 크레듀는 안산 영어마을 위탁운영 사업자로 선정됐으 며 이후 수익을 내기 위해 성인들이 영어교
육을 받을 수 있도록 성인동을 건설하는 등 새로운 시도를 하고 있다. 학생들이 주로 월 요일부터 금요일까지 영어마을에 들어오기 때문에 금요일 오후부터 토요일까지 1 박 2일 일정으로 기업체 직원 대상의 영어연수 프로 그램을 만들어 가동률을 높이기 위한 것이다. 현재 영어마을 운영비로 연간 50억 원 정도 가 소요되지만, 기존 학생 대상 교육만으로는 10 20억 원의 적자가 날 수밖에 없다고 판단, 성인 대상 프로그램을 마련했다. 또 기업체 체육대회나 조직 활성화 프로그램, 승격교육 등을 적극 유치해 주말에도 시설 활용도를 높인다는 계획이다.

크레듀는 또한 중등 온라인 교육시장에도 진출했다. 2007년 4월 최종 의사결정이 이루 어져 크레듀M이란 자회사를 설립했고 그해 9월 웹사이트를 개설했다. 온라인 중등 교육 시장은 메가스터디 같은 절대 강자가 포진하 고 있다. 하지만 크레듀는 기업 시장에서의 강점을 바탕으로 중등 교육에 진출하는 전략 을 수립했다. 즉, 기업들이 사원 복지 정책의 일환으로 임직원 자녀 교육을 지원하는 프로 그램을 만들도록 유도해 회원을 확보, 수익을 내겠다는 방침을 세웠다. 다른 온라인 중등 교육 업체처럼 기업과 소비자 간의 거래 $(\mathrm{B} 2 \mathrm{C}$ : Business-to-Customer)시장에서 승부하는 게 아니라 기업과 기업 간의 거래(B2B : Businessto-Business) 시장을 공략하는 차별적 영업 전략을 수립한 것이다. 크레듀가 이런 접근을 한 것은 $\mathrm{B} 2 \mathrm{C}$ 시장에 강력한 경쟁자가 포진 해있는데다 일반 학생을 대상으로 사업을 할 경우 막대한 홍보비 등을 지출해야하기 때문 이다. 크레듀는 2008년부터 기업 대상의 영업 을 본격화해 삼성전자 지방 사업장에 근무하 
는 임직원 자녀를 대상으로 회사와 직원이 각각 절반씩 비용을 대서 교육 콘텐츠를 공 급하기로 했다. 또 삼성중공업도 이와 유사한 프로그램을 도입했다. 크레듀 $\mathrm{M}$ 은 사교육비 가 워낙 많이 들어가는 상황에서, 기업이 자 녀 교육비를 지원할 경우 임금임상을 해주는 것과 사실상 같은 효과를 낼 수 있다며 기업 대상 영업을 강화하고 있다.

\section{4. e러닝 시장의 활성화 방안}

\section{$4.1 \mathrm{e}$ 러닝 시장의 위험 요소}

크레듀의 사례와 같이 e러닝 시장에서의 기 업들은 차별적 경쟁우위를 달성하기 위해 핵 심 사업 분야에서의 역량 강화와 이를 토대 로 구축된 핵심역량을 활용한 사업다각화를 꾸준히 추진해왔다. 하지만 경쟁은 갈수록 심 화되고 있으며 사업의 구조적인 불안 요인도 여전하다. 무엇보다 이러한 e러닝 기업은 정 부의 고용보험 환급 정책에 지나치게 의존하 고 있다. 고용보험 환급과 관련한 매출이 대 부분을 차지하고 있기 때문에 정부 정책이 변할 경우 사업의 기반이 무너질 수도 있다. 또 노동부의 기관평가 결과에 따라 사업의 수익성이 크게 좌우되는 구조를 갖고 있다. 뿐만 아니라, e러닝 시장은 초기부터 줄곧 경 쟁 강도가 매우 강했다. 온라인 교육에 대해 서도 고용보험 환급이 이뤄지면서 크레듀, 배 움닷컴, 아이빌소프트가 유사한 사업 모델로 경쟁을 벌였고, 시스템 및 솔루션 시장에서 또한, 다울소프트, $4 \mathrm{C}$ 소프트 등이 경합을 벌 였다. 크레듀의 성공에 자극받은 대기업들이
잇따라 유사한 성공 모델을 만들기 위해 이 사업에 뛰어든 것이다. 대기업의 경우 계열사 들을 통해 안정적인 수익을 올릴 수 있다는 장점이 있기 때문에 대기업 계열사가 더 많 이 진출할수록 중소 $\mathrm{e}$ 러닝 업체의 잠재 시장 규모는 줄어들 수밖에 없는 상황이다. 경쟁 강도가 강하기 때문에 입찰 경쟁도 불붙고 있다. 입찰을 따내기 위해 수강료를 대폭 할 인해주는 사례도 속속 등장하고 있다. 또 경 쟁 격화로 공공부문 콘텐츠 개발 사업의 경 우 마진율이 한 자릿수 이하로 낮아졌다. 외 국어 교육 과정을 공급하는 일부 중소 업체 들이 시장 질서를 파괴할 정도로 파격적인 저가 정책을 펴기도 했다.

\section{2 e러닝 시장 활성화 방안}

앞서 언급한 것처럼 $\mathrm{e}$ 러닝 시장은 엄청난 경 쟁 기업과 자원 고갈 등으로 이미 산업 플랫폼 이 레드 오션으로 간주되고 있는 상황이다. 이 러한 상황 속에서 학습요인동기를 높이고 미래 의 수익 모델을 찾기 위하여 지금까지와 같이 $\mathrm{e}$ 러닝 서비스를 지속적으로 개선하고 새로운 기술을 개발하는 기존 전략을 버리고, 소위 파 괴적 혁신(Disruptive Change)를 통한 현재 서 비스의 기능에는 미치지 못할지라도 새로운 보 급형 (low-end) 서비스를 도입해 기존 시장을 파괴하고 새로운 시장을 창출하는 방안을 마련 하는 법을 강구할 필요가 있다. 이를 위해, 크레 듀의 사례에서 크레듀 $\mathrm{M}$ 의 성장을 핵심 과제로 정해 영업 역량을 총동원하는 것처럼, 일반 직 장인이 아닌 중고등학교 학생들을 대상으로 $\mathrm{LMS}$ 기술 등 자체 핵심역량을 바탕으로 다양 하고 독특한 서비스를 제공할 수 있다. 또 다른 
크레듀의 미래 핵심 사업으로 향후 듣기 위주 의 영어 교육이 아닌, 말하기 위주의 영어 교육 이 더욱 활성화됨에 따라, $\mathrm{OPIc}$ 사업과 같은 새 로운 잠재 혁신 모델을 개발하고 활성화할 필 요가 있다. 뿐만 아니라, 우리나라에서만 머물 것이 아니라, 국제화를 적극 모색하여 해외 법 인을 대상으로 e러닝 서비스를 제공할 수 있도 록 강구하고 향후 더욱 개발 자원이 풍부한 중 국이나, 동남아시아 같은 개발도상국에 다양한 국제 원조 자금을 활용하여 교육 사업 투자 모 델을 수립할 수 있다.

\section{5. 결 론}

크레듀의 사례를 중심으로 $\mathrm{e}$ 러닝 시장에서 학습자의 다양한 학습동기유형에 따른 전략 과 그에 따른 서비스를 살펴보았다. e러닝 시 장은 기존의 오프라인 교육시장과 차별화하 여 ICT를 통한 시장 개척이 이루어졌으며, 지금도 지속적으로 진화하고 있다. 하지만, e 러닝 시장의 치열한 경쟁으로 인해 수익 모 델이 점차 줄어들고 있는 것도 사실이다. 이 러한 가운데, 크레듀는 핵심역량을 유지하고 강화하기 위해 고객과 적극적인 의사소통 채 널을 만들어 핵심 사업 분야에 대한 집중적 인 투자를 단행하면서 모험적이고 실험적인 제품과 서비스를 출시해 e러닝 발전에 기여 했으며 기업의 성장세를 이어갔다. 본 연구는 소비자의 e러닝 학습동기유형을 분류한 선도 적인 연구일 뿐만 아니라 성공한 e러닝 기업 의 사례를 통한 $\mathrm{e}$ 러닝 시장의 개척과 확산 방안에 관한 기법을 소개함으로써 실무적인 측면에서 그 가치가 높을 것으로 기대한다.

\section{References}

[1] Baltes, M. M. and Lang, F. R., "Everyday functioning and successful aging : The impact of resources," Psychology and Aging, Vol. 12, pp. 433-443, 1997.

[2] Baltes, P. B., "Psychology of perspectives on successful aging : The model of $\mathrm{se}^{-}$ lective optimization with compensation, Perspecitves from the behavior science (pp. 1-34)," Cambridge University Press, 1990.

[3] Bandura, A., "Self-efficacy, The Exercise of Control," New York : Freemann, 1997.

[4] Bates, A. and Poole, G., "Effective Teaching with Technology in Higher Education," San Francisco : John Wiley, 2003.

[5] Baumeister, R. F. and Leary, M. R., "The need to belong : Desire for interpersonal attachments as a fundamental human motivation," In E. T. Higgins and A. W. Kruglanski (Eds.), Motivational Science, Social and personality perspectives (pp. 24-49). New York : Psychology Press, 2000.

[6] Choi, H. R., "An Empirical Study on Factors Influencing the Learning Effects of E-Learning : The Case of E-Learning Service of 'P' Company," Society for $\mathrm{e}^{-}$ Business Studies, Vol. 10, No. 2, pp. 59-88, 2005.

[7] Duch, B. J., GRoh, S. E, and Allen, D. E., "The Prower of Problem-based Learning 
: A Practical "How to" for Teaching Undergraduate Course in any Discipline," Stylus Publishing, 2001.

[8] Heckhausen, J. and Dweck, C. S., "Motivation and Self-Regulation across the Life Span," Cambridge : Cambridge University Press, 1998.

[9] Heckhausen, J. and Heckhausen, H., "Motivation und Handeln," Heidelberg : Springer Medizin Verlag, 2006.

[10] Heckhausen, J. and Schulz, R., "A lifespan theory of control," Psychology Review, Vol. 102, pp. 284-304, 1995.

[11] Huang, C.-H., Lee, L.-Y., and Chang, M.-L., "The influence of personality and motivation on exercise participation and quality of life," Social Behavior and Personality, Vol. 35, pp. 1189-1210, 2007.

[12] Im, B. N. and Lee, J., "The study on present state of e-learning contents and its implication for higher education," Educational Information Media, Vol. 13, No. 2, pp. 277-307, 2007.

[13] Kelemen, V. P., Achievement and affiliation : A motivational perspective of sex differences. Social Behavior and Personality, Vol. 8, pp. 1-11, 1980.

[14] Kim, H. Y., "Psycological base of e-learning," Hakjisa Co., 2007.

[15] Kim, J. W. and Nam, K. C., "Effect of Online Education on Training Effectiveness : Conceptual Framework and Empirical Validation," Society for e-Business Studies, Vol. 12 No. 4, pp. 185-209, 2007.
[16] Krapp, A., "Interest, motivation and learning : An educational-psychological perspective," European Journal of Psychology of Education, Vol. 14, No. 1, pp. 23-40, 1999.

[17] Krapp, A., "An educational-psychological conceptualisation of interest," International Journal for Educational and Vocational Guidance, Vol. 7, No. 1, pp. 5-21, 2007.

[18] Kunzmann, U., "Differential age trajectories of positive and negative affect : Further evidence from the berlin aging study," Journal of Gerontology : Psychological Sciences, Vol. 63B, pp. 261-270, 2008.

[19] Mayr, U., Wozniak, D., Davidson, C., Kuhns, D., and Harbaugh, W. T., "Competitiveness across the life span : The feisty fifties," Psychology and Aging, Vol. 27, pp. 278-285, 2011.

[20] Means, B., Toyama, Y., Murphy, R., and Bakia, M., Evaluation of Evidence-Based Practices in Online Learning : A MetaAnalysis and Review of Online Learning Studies, 2009.

[21] Park, C. U. and Kang, I. W., "The study on the optimized e-learning environment through contents systematization," knowledge management, Vol. 11, No. 1, pp. 115-128. 2010.

[22] Piccoli, G., Ahmad, R., and Ives, B., "Web-based Virtual Learning Environments : A Research Framework and a Preliminary Assenssment of Effectiveness in Basic IT Skills Training," MIS 
Quarterly, Vol. 25, No. 4, pp. 401-425. 2001.

[23] Sampo, V., "Paunonen, Big Five Factors of Personality and Replicated Predictions of Behavior," Journal of Personality and Social Psychology, Vol. 84, No. 2, pp. 411-424, 2003.

[24] Sweller, J., van Merrienboer, J. J. G., and Paas F. G. W. C., "Cognitive Load and Selective Attention as Factors in the Structuring of Technical Material," Journal of Experimental Psychology, Vol. 119, pp. 176-192, 1998.

[25] Tam, K. Y. and Ho, S. Y., "Understanding the Impact of Web Personalization on User
Information Processing and Decision Outcomes," MIS Quarterly, Vol. 30, No. 4, pp. 865-890, 2006.

[26] Voigt, C. and Swatman, P. M. C., "Learning through Interaction : Improving Practice with Design-based Resaerch," International Journal of Interactive Technology and Smart Education, Vol. 3, No. 3, pp. 207-224. 2006.

[27] Vroom, V. H., Work and Motivation, New York : Wiley, 1964.

[28] Wang, Y. S., “Assessment of Learner Satisfaction with Asynchronous Electronic Learning Systems," Information and Management, Vol. 41, pp. 75-86, 2003. 


\section{저 자 소 개}

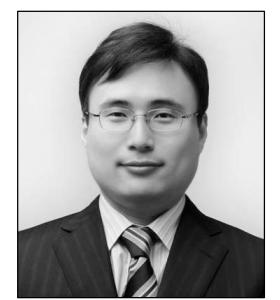

김남국

1995년

2002년

2009년

2010년 현재

2012년 현재

관심분야

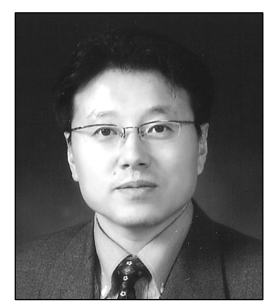

이준기

1985년

1991년

1999년

2004년 현재

관심분야
(E-mail : march@donga.com)

고려대학교 철학과 (학사)

헬싱키경제경영대학교(현 알토대) $\mathrm{EMBA}$ (석사)

연세대학교 국제학대학원 국제경영학과 (박사)

$\mathrm{DBR}$ (동아비즈니스리뷰) 편집장

한양대학교 경영대학 겸임교수

Global Strategy, Open Innovation, SME Strategy

(E-mail : zoonky@gmail.com)

서울대학교 전산통계학과 (학사)

카네기멜론대학 사회심리학과 (석사)

남가주대학교 경영정보학과 (박사)

연세대학교 정보대학원 교수

Web2.0 and Business, Service Science, Value Innovation, E-Transformation, Dynamic Pricing, KM, Open Innovation, Open Collaboration, Big Data

(E-mail : afchang@naver.com)

대한민국 공군사관학교 졸업-공사43기 (학사)

연세대학교 대학원 경영학과 경영정보학 (석사)

연세대학교 대학원 경영학과 전략경영 (박사)

대한민국 공군사관학교 리더십학과 교수

Business Strategy, Strategic Leadership, Information

Strategy

(E-mail : halfmoonlike@gmail.com)

연세대학교 응용통계학과 (학사)

카네기멜론대학 컴퓨터공학과 (석사)

연세대학교 정보대학원 (박사과정)

Servicization, Big Data, e-Learning, 